\title{
Relacionamento interorganizacional na cadeia de suprimentos: um estudo de caso na indústria da construção civil
}

\author{
Renata Albergaria de Mello Bandeira UFRGS \\ Luiz Carlos Brasil de Brito Mello UFF \\ Antonio Carlos Gastaud Maçada UFRGS
}

\section{RESUMO}

O escopo deste trabalho consiste em promover uma discussão sobre os mecanismos de coordenação das relações interorganizacionais - poder e cooperação - na cadeia de suprimentos da indústria da construção civil. 0 poder, como um construto de relações interorganizacionais, tem recebido um tratamento irregular e conflitante por parte dos analistas. No entanto, esta abordagem ignora relações existentes que são muito apropriadas para certos contextos do relacionamento interfirmas. Logo, foi desenvolvido um estudo de caso em um elo da indústria da construção civil com o intuito de identificar suas relações como sendo baseadas em dominação ou cooperação. São analisadas, ainda, as implicações dos resultados da pesquisa na gestão da cadeia de suprimentos da construção civil.

PALAVRAS-CHAVE

Cadeia de suprimentos, aliança estratégica, relacionamento, construção civil.

\section{The interorganizational relationship in the supply chain: a case study in the civil construction industry}

\begin{abstract}
The article discusses the relationship in the supplier chain in the civil construction industry. The main objective is to define if it is a cooperative relation among the intervenients or if the most powerful dictates the rules. Power as an interorganizational construct has been observed by analysts with an irregular and conflictive point of view. However, these analysts ignore completely existing relationships that are very appropriate in some existing relationships among enterprises. Due to that, it was verified het type of relationship developed by two intervenients in one step of the supply chain of a civil construction company to determine if it is cooperative or if, otherwise, the main actor uses its power to lead the chain. The researchers also analyze what are the implications of this study in the civil construction industry's supply management.
\end{abstract}

\section{KEY WORDS}

Supply chain, strategic alliances, relationship, civil construction. 


\section{INTRODUÇÃO}

O relacionamento nas cadeias de suprimento é um tópico estratégico para o sucesso das empresas, sendo fundamental a compreensão das estruturas dos relacionamentos existentes para que os profissionais de logística saibam como as cadeias devem ser gerenciadas.

A literatura de logística considera que o relacionamento da cadeia ocorre apenas com base na cooperação e na confiança (BOWERSOX; CLOSS, 2001; COUGHLAN et al., 2002). De tal maneira, a literatura foca essencialmente em relações de cooperação entre compradores e fornecedores, buscando soluções ótimas para a minimização de custos (MILLS et al., 2004). Entretanto, os relacionamentos em uma cadeia de suprimentos são relações de risco, poder, liderança e cooperação.

A gestão da cadeia de suprimentos considera as dimensões comportamentais e políticas do poder e da confiança, além do conflito e dependência entre fornecedores e compradores. Estudos recentes apontam a relevância do poder e da dominação como construtos nas relações em cadeias de suprimento. Contudo, Cox (1999) relata haver pouca discussão sobre esta questão. Recentemente, o tema passa a ter maior relevância na academia, sendo trabalhado por autores como Cox (1999), Cox e Chicksand (2005) e Hingley (2005).

Através deste trabalho, pretende-se promover uma discussão a respeito da importância dos relacionamentos na cadeia de suprimentos, tentando identificá-los como relações de dominação ou cooperação. Assim, a pesquisa busca responder à seguinte questão: o relacionamento dominante em uma cadeia de suprimento da construção civil é de dominação ou de cooperação? Para tanto, são analisados, por meio de um estudo de caso, os relacionamentos em um elo da cadeia de suprimentos da construção civil.

A relevância do estudo é justificada pela importância da indústria da construção civil no panorama econômico brasileiro. O setor é estratégico para as políticas públicas de geração de riquezas e criação de empregos, sendo responsável por $19 \%$ do Produto Interno Bruto nacional e por 6\% dos salários pagos aos trabalhadores (Câmara Brasileira da Indústria da Construção, 2005). Além disto, a indústria da construção civil age sobre uma extensa cadeia produtiva de fornecedores, serviços de comercialização e manutenção. Desta forma, as relações interorganizacionais são uma realidade no setor que influencia o desempenho das empresas do ramo. Assim, é essencial que os gestores compreendam os possíveis arranjos empresariais que podem ser estabelecidos, bem como a estrutura de tais relacionamentos.
A primeira parte desta pesquisa traz os conceitos de cooperação, poder e dominação para, então, analisar suas influências no relacionamento entre os membros das cadeias de suprimentos. Realiza-se, então, por meio de um estudo de caso, uma análise sobre relações de suprimentos entre empresas da cadeia de construção civil. Finalmente, são apresentadas as conclusões e sugestões para novos trabalhos.

\section{OS MECANISMOS DE COORDENAÇÃO NAS RELAÇÕES NA CADEIA DE SUPRIMENTOS}

Nesta seção é abordada a conceituação dos mecanismos de coordenação dos relacionamentos interorganizacionais a cooperação, a confiança, o poder e a dominação. Também é analisada a influência destes mecanismos nas relações entre os membros das cadeias de suprimentos.

\subsection{Conceituação de confiança e de cooperação}

A confiança é um componente importante que torna bem-sucedidas as relações interorganizacionais. Em geral, a confiança é tratada pela literatura com base em aspirações filosóficas e em uma visão harmônica, fundamentada na benevolência e no altruísmo (NIELSEN, 2004). No entanto, analistas críticos rejeitam esta posição, considerando que a confiança é uma ferramenta sofisticada para o exercício do poder à medida que o parceiro mais forte utiliza a confiança para reduzir a incerteza do ambiente e transferir o risco para o parceiro mais fraco. Bachmann (2001) salienta que tais perspectivas marcam os extremos do mainstream do debate teórico sobre confiança. Porém, nenhum destes enfoques aborda a complexidade do processo social que determina a lógica do relacionamento interorganizacional. Para tanto, é preciso analisar as tensões e contradições entre os conceitos de confiança e poder.

Não existe uma definição única para o conceito de confiança. Alguns autores a veem como sendo a expectativa sobre o modo de atuação desejado do confiado, enquanto outros a definem em termos da avaliação sobre a boa vontade e a confiabilidade do outro em uma situação de risco (NIELSEN, 2004). Tal divergência conceitual fundamenta as discussões sobre o papel da confiança nas transações econômicas entre estudiosos das correntes de orientação comportamental e econômica. A discussão está, basicamente, no processo através do qual a confiança emerge nas transações (BARNEY; HANSEN, 1994).

De acordo com Bachmann (2001), a economia tradicional não contribui para o debate teórico sobre confiança. $\mathrm{O}$ autor aponta que a Teoria dos Custos de Transação, fundamentada nas decisões entre hierarquia e mercado e na redução do 
oportunismo, é muito simplista para explicar as recentes transações e estratégias econômicas. Ele também considera que os pressupostos da Teoria dos Jogos não podem ser aplicados para entender o papel da confiança nas relações interorganizacionais. A teoria proposta por Axelrod (1983) pressupõe que o comportamento dos atores econômicos é determinado por especulação. Contudo, devido à natureza da confiança, Bachmann (2001) afirma não ser possível medir o potencial de perda ou ganho deste tipo de relação, dado que a previsibilidade das consequências das decisões tomadas implicaria em uma situação onde a confiança não seria mais necessária.

\section{fundamental a compreensão das estruturas Edos relacionamentos nas cadeias de suprimento para que os profissionais de logística saibam como gerenciá-las.}

Barney e Hansen (1994) apresentam uma abordagem sobre o conceito de confiança que rejeita, simultaneamente, as ideias das correntes comportamental e econômica. Os autores não creem que todas as partes de uma transação são oportunistas e nem que elas sejam confiáveis na maior parte do tempo. Assim, ao invés de assumir posições extremas em relação às partes de uma transação, é necessário compreender que o comportamento das partes pode variar e a variância do grau de confiança possibilita vantagens competitivas.

Bachmann (2001) classifica a confiança em pessoal ou sistêmica. A confiança pessoal é o fenômeno de nível individual, enquanto a sistêmica ocorre no nível organizacional. Para o autor, a confiança pessoal é importante em certas situações, sendo essencial no início das relações. O contato face a face ajuda a reduzir o risco, além de ser importante na constituição da confiança, porém não é suficiente para produzir a confiança sistêmica, não sendo capaz de se sustentar como o principal meio de confiança do relacionamento.

Segundo Nielsen (2004), embora sejam conceitos distintos, a confiança interpessoal e interorganizacional estão relacionadas. $\mathrm{O}$ autor aponta que a confiança interorganizacional (sistêmica) emerge como um direcionador do desempenho das trocas e negociações, estando associada à diminuição dos custos de negociação. Em contraste, a confiança interpessoal mostra uma associação proporcional a esses custos. Assim, a pesquisa de Nielsen (2004) corrobora a proposta de Bachmann (2001) de que a confiança pessoal não é capaz de se sustentar como o principal meio de con- fiança no relacionamento entre firmas.

Em seu estudo, Nielsen (2004) examina a evolução da confiança e seu impacto nos relacionamentos colaborativos. Como a confiança é uma variável dinâmica, o autor reforça a importância da avaliação do papel da confiança nas diferentes fases de relacionamento colaborativo.

É comum encontrar na literatura o conceito de confiança associado ao de cooperação. Para La Porta et al. (1997), a confiança implica a propensão a cooperar. Hagen e Choe (1998) sugerem que a cooperação é aparentemente induzida pela confiança. Contudo, outros mecanismos institucionais e sociais, aliados à confiança, são essenciais para conduzir os relacionamentos interorganizacionais.

Os estudos sobre cooperação recaem sobre várias frentes, seja no campo da Sociologia, da Economia ou da Teoria Organizacional. Em termos de abordagens teóricas, Begnis et al. (2005) constatam que, até o final da década de 90 , predominam a Economia dos Custos de Transação e as Teorias Organizacionais de modo geral, em especial sob o ponto de vista do Aprendizado Organizacional. Os autores também destacam os enfoques trazidos pela Teoria das Redes Sociais para o avanço dos estudos sobre relacionamentos cooperativos interorganizacionais, acrescentando que ainda há um vasto espaço para discussão da confiança na base destes relacionamentos.

\subsection{Conceituação de poder e dominação}

A confiança não é a única forma de reduzir a complexidade e incerteza nas relações interorganizacionais. Outro possível mecanismo para coordenar as expectativas e controlar a dinâmica das relações é o poder.

Tanto o poder quanto a confiança permitem a coordenação das expectativas e das ações das partes negociantes. Contudo, Bachmann (2001) reforça que tais mecanismos diferem quanto ao modo de seleção das expectativas. Os atores que optam por fundamentar suas relações na confiança consideram que as demais partes se comportarão da forma esperada. Porém, se a parte mais forte considerar que o membro mais frágil não se comportará conforme a expectativa, esta pode utilizar sanções e punições para controlá-lo. Este tipo de relacionamento está sujeito a um mecanismo frágil, dado que o risco de término súbito da confiança nunca pode ser totalmente eliminado. O poder, assim como a confiança, também pode entrar em colapso se ameaçado massivamente. No entanto, as consequências não são tão severas e o relacionamento pode continuar depois deste evento, uma vez que o poder não tem uma carga emotiva como a confiança. Apesar de conseguir reduzi-los consideravelmente, o poder também traz riscos. 
O conceito de poder é compreendido a partir de diferentes denotações. Faria (2004) ressalta a relevância do tema nos estudos organizacionais e reforça que o conceito de poder deve ter seu próprio espaço teórico e lugar epistemológico. Entretanto, esta não é uma prática frequente no âmbito da teoria organizacional, na qual o conceito de poder "não só é utilizado como sendo equivalente aos de liderança, influência, autoridade ou coerção, como é usado com mais de um sentido ao mesmo tempo" (FARIA, 2004). Assim, o autor apresenta uma análise sobre o conceito de poder, abordando os principais enfoques que estruturam teórica e epistemologicamente a análise das organizações: (i) enfoque sistêmico-funcionalista; (ii) weberiano; (iii) do comportamento humano; (iv) organizacional; (v) marxista; e (vi) da psicossociologia.

Segundo Faria (2004), estudar a sociologia do poder em Weber implica em estudar os conceitos de dominação, obediência e disciplina, tanto quanto compreender as noções de autoridade, coerção e legitimidade. Sob este enfoque, a coação, a autoridade e a influência são consideradas as bases do poder.

Há várias correntes que tratam o poder sob o ponto de vista do comportamento humano. Sob o enfoque behaviorista, Dahl (1968, apud FARIA, 2004) refere-se ao poder como sendo a capacidade de A levar B a fazer algo que não faria de outro modo, considerando o exercício unilateral do poder, sem resistências ou motivações subjetivas. French e Raven (1959) aprofundam a formulação de Dahl ao acrescentar as cinco bases que permitem medir a amplitude e o grau de dependência entre A e B: (i) poder de recompensa; (ii) poder coercitivo; (iii) poder legítimo; (iv) poder referente; $\mathrm{e}$ (v) poder de especialização.

O enfoque organizacional tem como base o estudo desenvolvido por March e Simon (1979, apud FARIA, 2004), que, inspirado na teoria da firma, trata o poder sob o ambiente de incerteza do processo decisório. Para Friedberg (1995, apud FARIA, 2004), não há ação social sem poder, sendo que todo o poder supõe uma relação de troca em um jogo com regras definidas que regulam a ação. Assim, a proposta de Friedberg salienta o elo entre poder e dependência, enfatizando a cooperação e a troca com a finalidade de realizar um objetivo comum a todos os atores envolvidos.

No presente trabalho, não é apresentado o conceito de poder sobre todos os enfoques propostos por Faria (2004). Limitou-se o foco nos autores citados na literatura que analisa o relacionamento nas cadeias de suprimentos. Desta forma, ainda deve-se apresentar a interpretação de Follet (1997) sobre o conceito de poder. Para a autora, o poder é geralmente compreendido como poder-sobre, ou seja, o poder de alguma pessoa ou grupo sobre outra. Follet (1997) apresenta o conceito de poder-com, que é desenvolvido con- juntamente, sendo compartilhado e não coercitivo. O podercom origina-se da união de poderes individuais, sendo que cada membro do grupo tem poder exclusivo e soberano, derivado da combinação de conhecimento, experiência e habilidades específicas. Não é sempre possível livrar-se do poder-sobre para estabelecer o poder-com. No entanto, deve-se tentar reduzi-lo através da integração.

Apesar de serem tratados por diferentes enfoques, os conceitos de poder, em linhas gerais, referem-se à "condição de realização de uma ação que, sem que lhe seja emprestada qualquer direção, não se viabilizaria. Esta condição pode ser obtida pela coerção, autoridade, influência, dependência ou pelo domínio psicológico, com ou sem resistência, baseada em um sistema de regras ou contratos, em negociação ou imposição (FARIA, 2004)". Destaca-se que a literatura de logística, em sua grande maioria, adota o conceito geral de poder, e este é o critério seguido neste trabalho.

\subsection{A influência dos mecanismos de coordenação no relacionamento entre membros da cadeia de suprimentos}

A confiança e o poder, de acordo com Bachmann (2001), são os principais mecanismos de coordenação das relações interorganizacionais, independentemente do arranjo que estrutura tal relacionamento. Segundo o autor, as relações de curto prazo, em geral, têm o oportunismo como base e são orientadas pelo controle central, enquanto relações de longo prazo, tal como costumam ser as relações estabelecidas nas cadeias de suprimento, tendem a se fundamentar na cooperação. Nesta seção, é discutida a influência dos mecanismos de coordenação nos relacionamentos entre membros da cadeia de suprimentos.

Os conceitos de risco, poder e liderança são essenciais para a compreensão das relações na cadeia de suprimentos. Para Bowersox e Closs (2001), o risco desproporcional entre membros da cadeia é central para a determinação da maneira como os relacionamentos são desenvolvidos e gerenciados. Alguns membros da cadeia têm maior dependência do sucesso da cadeia que outros. Assim, os membros com maior risco devem assumir papéis mais ativos e maior responsabilidade para a viabilização da cooperação na cadeia.

A cadeia de suprimentos é formada por participantes que dependem uns dos outros. Porém, a dependência nunca acontece completamente em uma direção. $\mathrm{Na}$ realidade, ocorre a interdependência. A dependência mútua entre os membros da cadeia incentiva a cooperação. Chopra e Meindl (2003) destacam que devem ser evitados relacionamentos em que uma parte seja mais dependente que a outra. Nos casos de relacionamentos assimétricos, a parte mais fraca e mais dependente assume maior risco. Em situações como 
esta, os membros mais fracos podem abandonar a cadeia ou procurar reduzir sua dependência através de alternativas de negócios, organizando coalizões contra a parte mais forte. Porém, o mais comum é que a parte mais dependente aceite a situação, não tendo nenhuma reação (COUGHLAN et al., 2002). Na realidade, muitos relacionamentos de dependência desequilibrada funcionam bem, principalmente em ambientes estáveis.

\section{$\Delta$ confiança e o poder são os principais Imecanismos de coordenação das relações interorganizacionais, independentemente do arranjo que estrutura tal relacionamento.}

São diversas as formas através das quais empresas mais fortes podem exercer dominação sobre os demais membros da cadeia. Entende-se por empresas mais fortes aquelas que têm um papel central na relação, não sendo substituíveis. Em geral, estas detêm o controle financeiro do relacionamento. Munson et al. (1999) afirmam que as empresas podem exercer o controle através de cinco áreas: (i) controle de preços; (ii) controle da estrutura do canal; (iii) controle de operação; (iv) controle da informação; (v) controle de inventário. É notório que empresas como a Wal-Mart, devido ao seu tamanho e papel central na cadeia, exercem o controle de preços, exigindo descontos de seus fornecedores. Porém, firmas de menor porte também podem se aliar para ampliar seu poder de barganha nas negociações.

Devido ao controle sobre a estrutura da cadeia exercido pela Wal-Mart, a empresa conseguiu eliminar representantes e intermediários de suas negociações, exigindo contato direto com indústrias manufatureiras. Algumas empresas abusam do controle da estrutura da cadeia para limitar a competição. Com relação ao controle da operação, as firmas têm imposto cada vez mais requerimentos sobre a qualidade dos produtos adquiridos. Em pesquisa desenvolvida por Munson et al. (1999) em 126 firmas de médio porte, verificou-se que $76 \%$ das entrevistadas haviam eliminado fornecedores que se recusaram a elevar o padrão de qualidade de seus produtos.

Uma das principais vantagens da cooperação entre membros de uma cadeia de suprimentos é o maior compartilhamento de informações. No entanto, no caso de concentração da informação, os membros que detêm mais informação e possuem melhor estrutura de Tecnologia da Informação exercem maior controle sobre a cadeia. Em geral, a troca de informações nas cadeias ocorre através de sistemas eletrônicos (eletronic data interchange - EDI). Apesar da existência de padrões internacionais de EDI, muitas empresas desenvolvem sua própria interpretação dos dados. Assim, as firmas menores são obrigadas a adaptar seus sistemas segundo os padrões dos membros mais fortes da cadeia. Em pesquisa realizada por Munson et al. (1999), 55\% das firmas entrevistadas declararam ter adotado o sistema EDI devido à pressão de seus principais fornecedores ou clientes.

Cox (2005) apresenta uma matriz com as possíveis relações entre membros de diferentes estágios da cadeia de suprimentos. A classificação é ilustrada na Figura 1. A partir da análise da Figura 1, verifica-se que as relações variam de acordo com a estrutura e características da cadeia. Desta forma, nem sempre as práticas adotadas em uma cadeia poderão ser replicadas com sucesso em outras configurações. Portanto, os profissionais de logística devem atentar que não há uma única forma correta de gerenciamento das cadeias de suprimentos. Para cada caso, devem ser adotadas diferentes práticas.

Para Hingley (2005), o comprador costuma ser a parte favorecida em relacionamento assimétrico. Entretanto, isto não impede que o membro mais fraco também se beneficie desta relação. Na verdade, as relações assimétricas ocorrem mais frequentemente que aquelas baseadas em cooperação e confiança. Em geral, os membros mais fracos da cadeia costumam tolerar esta situação em virtude das vantagens que ela lhes proporciona (devido ao poder de recompensa, segundo o conceito de French e Raven). Pelo enfoque da teoria econômica, esta situação se sustenta porque minimiza os custos de transação. Assim, relações assimétricas são legitimadas, podendo ser estáveis e duradouras. Segundo a abordagem weberiana, estas seriam classificadas como relações de dominação e autoridade.

Berthon et al. (2003) consideram o poder e a dominação como mecanismos que devem ser utilizados para atingir a coordenação e a cooperação entre os membros da cadeia. Hingley (2005) reforça que as relações de poder e cooperação coexistem, sendo parte do mesmo construto. Como exemplo, $\mathrm{o}$ autor cita as alianças formadas por empresas de pequeno $\mathrm{e}$ médio porte para negociação com membros mais fortes. Deste modo, o conceito de "poder-com" de Follet (1997) é perfeitamente compatível com a natureza das cadeias de suprimento, pois supõe a existência de cooperação e colaboração entre os membros para construção dos resultados.

A maioria das relações interorganizacionais se baseia em uma mistura de poder e confiança. Estes construtos também são os mecanismos de coordenação dos relacionamentos em cadeias de suprimentos. Contudo, Bachmann (2001) ressalta 
que tais mecanismos são limitados no que concerne ao controle da estrutura e da dinâmica das relações, de modo que a combinação é apontada como a melhor forma de coordenação das expectativas dos membros da cadeia de suprimentos.

A seguir, são analisadas as relações de suprimentos entre uma empresa da construção civil e um fornecedor de pequeno porte, buscando-se compreender o relacionamento entre membros de diferentes estágios da cadeia de suprimentos da construção civil.

\section{METODOLOGIA}

Esta pesquisa tem cunho qualitativo, sendo adotado o estudo de caso como estratégia de investigação. Seu escopo consiste em identificar como se estruturam os relacionamentos entre os membros de diferentes estágios da cadeia de suprimentos da construção civil. Assim, o trabalho busca responder à seguinte questão: o relacionamento dominante em uma cadeia de suprimentos da construção civil é de dominação ou de cooperação?
É importante ressaltar que foi realizado o estudo de apenas um caso, de modo que os resultados obtidos não podem ser generalizados. A pesquisa não permite responder à questão para toda a cadeia de suprimentos da construção civil, mas apenas para o caso estudado. Entretanto, Yin (2001) afirma que, embora os resultados de um estudo de caso não possam ser generalizados, devem possibilitar a disseminação do conhecimento a partir da compreensão e interpretação de fatos e fenômenos, normalmente isolados, de maneira mais profunda. É o que se espera ter alcançado nesta pesquisa.

Esta pesquisa é de caráter exploratório, pois este ainda é um tema pouco estudado. Desta forma, o trabalho proporciona uma visão geral sobre o tema em estudo, levantando questões e hipóteses para futuros estudos.

O instrumento utilizado para desenvolvimento da pesquisa baseou-se no desenvolvido e validado por Mello (2007), cujo objetivo consiste em auxiliar o processo de avaliação dos relacionamentos interorganizacionais na cadeia produtiva da construção civil. Entretanto, foi necessário adaptá-lo para desenvolver o protocolo do estudo de caso, que contém um roteiro de entrevista semiestruturado. $\mathrm{O}$ roteiro foi subme-

\begin{tabular}{|c|c|c|}
\hline \multirow[b]{2}{*}{ ALTA } & Dominação exercida pelo Comprador & Interdependência \\
\hline & $\begin{array}{l}\text { - Poucos compradores/muitos fornecedores } \\
\text { - Dependência do fornecedor }\end{array}$ & $\begin{array}{l}\text { - Poucos compradores/poucos fornecedores } \\
\text { - Dependência do fornecedor }\end{array}$ \\
\hline \multirow{6}{*}{ 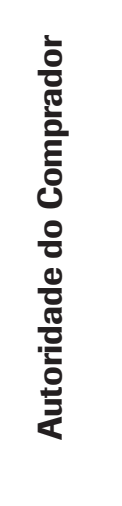 } & - Produtos comercializados são commodities & $\begin{array}{l}\text { - Produtos comercializados não são commodities, } \\
\text { tendo poucas opcões de fornecimento }\end{array}$ \\
\hline & $\begin{array}{l}\text { porcentagem das transações do fornecedor } \\
\text { - Custos de troca do fornecedor são baixos }\end{array}$ & $\begin{array}{l}\text { Relações com comprador representam alta } \\
\text { porcentagem das transações do fornecedor } \\
\text { - Custos de troca do fornecedor são altos }\end{array}$ \\
\hline & Independência & Dominação exercida pelo Fornecedor \\
\hline & - Muitos compradores/muitos fornecedores & - Muitos compradores/poucos fornecedores \\
\hline & - Produtos comercializados são commodities & - Não há dependência do fornecedor \\
\hline & $\begin{array}{l}\text { - Relações com comprador não representam alta } \\
\text { porcentagem das transações do fornecedor }\end{array}$ & $\begin{array}{l}\text { - Produtos comercializados não são commodities, } \\
\text { tendo poucas opções de fornecimento }\end{array}$ \\
\hline \multirow[t]{2}{*}{ BAIXA } & - Custos de troca de fornecedor são baixos & $\begin{array}{l}\text { - Relações com comprador representam baixa } \\
\text { porcentagem das transações do fornecedor }\end{array}$ \\
\hline & & - Custos de troca do fornecedor são altos \\
\hline
\end{tabular}

Autoridade do Fornecedor

Figura 1: Matriz de relações na cadeia de suprimentos.

Fonte: Adaptado de Cox, 2005 
tido à avaliação de três especialistas, um acadêmico da área de Estratégias Organizacionais e Interorganizacionais, um especialista em Novas Tecnologias para Engenharia Civil e um empresário do setor de Construção Civil. Estes avaliaram a compreensão e relevância das questões, assegurando a validade de face e de conteúdo.

Foi pesquisado o relacionamento entre membros da cadeia de suprimentos de construção civil. Esta escolha fundamenta-se no fato de que o setor age sobre uma extensa cadeia produtiva, onde as relações interorganizacionais influenciam o desempenho das empresas do ramo.

Inicialmente, procurou-se selecionar empresas de construção civil, atuantes no subsetor de edificações. Para minimizar as dimensões tempo e custo da pesquisa, devido à escassez de recursos para a realização de uma pesquisa mais ampla, decidiu-se restringir a mesma para empresas situadas no Estado do Rio de Janeiro. Foram listadas cerca de dezessete empresas que haviam colaborado com os pesquisadores em trabalhos anteriores. Estas empresas foram organizadas em uma lista, e a partir desta lista buscou-se contato com as empresas a partir da primeira da lista. Caso alguma delas não se dispusesse a participar, seguia-se para a próxima da lista. Apenas uma das empresas se dispôs a participar, e, mesmo assim, com a pré-condição de que não fosse identificada. A empresa que se dispôs a participar é uma das principais empresas do setor, o que contribui para a validade externa da pesquisa.

Na primeira reunião com a empresa de construção civil foi explicado o objetivo da pesquisa, ou seja, estudar se o relacionamento dominante na cadeia de suprimentos da construção civil é de dominação ou de cooperação. Houve dificuldades no entendimento da questão e foram necessárias algumas explicações para que se atingisse o pleno entendimento por parte dos envolvidos da empresa. Contudo, após o pleno entendimento do enfoque da pesquisa e da realização das entrevistas, foi indicado aos pesquisadores que da lista de fornecedores da empresa, a que melhor se enquadrava nos objetivos da pesquisa era a Metalúrgica Z. Não foi permitida a consulta à lista de fornecedores, alegando-se questões de sigilo e de intensas atividades junto aos mesmos buscando melhoria da qualidade. Os pesquisadores aceitaram a sugestão da construtora pela razão de que: a) esta foi a única das empresas consultadas disposta a colaborar na pesquisa; $\mathrm{e} b$ ) o fornecedor escolhido atua na fabricação e colocação das esquadrias e painéis metálicos, e este setor possui uma boa estruturação e relacionamento com as construtoras.

O contato com a Metalúrgica Z, para a aprovação do desenvolvimento do estudo de caso, foi realizado pela própria unidade de análise. A empresa selecionada também indicou quais seriam os entrevistados, atendendo à exigência de que fossem funcionários envolvidos com cadeias de suprimento e que, preferencialmente, participassem diretamente do relacionamento com a Metalúrgica Z. Após a primeira visita, onde foi explicada a metodologia da mesma, foi considerado mais conveniente que as próprias organizações indicassem os funcionários mais adequados a serem entrevistados para melhor atender os objetivos da pesquisa. Foram entrevistados um diretor e três gerentes da construtora. No fornecedor de painéis e esquadrias foram realizadas entrevistas apenas com o dono da empresa, por se tratar de uma empresa de pequeno porte. Nesta empresa havia apenas o dono, o encarregado e o pessoal de mão-de-obra direta.

O trabalho de pesquisa foi realizado no período de julho até setembro de 2007. A principal fonte de dados foram entrevistas semiestruturadas. As entrevistas foram gravadas e transcritas pelos pesquisadores, sendo realizada posteriormente a análise de conteúdo das entrevistas. A técnica de análise de conteúdo foi utilizada para analisar as informações obtidas através das entrevistas. Segundo Bardin (1977), a análise de conteúdo é um conjunto de técnicas de análise de comunicações que visa, através de procedimentos sistemáticos e objetivos de descrição das mensagens, obter indicadores que permitam a inferência de conhecimentos relativos às condições de produção e recepção destas mensagens.

Além das entrevistas realizadas, também foram adotadas fontes de evidências documentais, tais como os sites das empresas, reportagens e artigos escritos sobre o setor. A triangulação dos dados contribui para tornar o estudo de caso robusto e para aumentar validade do construto. A utilização de um protocolo de estudo de caso e o desenvolvimento do banco de dados também contribuiu para aumentar a confiabilidade da pesquisa (BENBASAT et al., 1987; YIN, 2001).

\section{ESTUDO DE CASO}

Nesta parte do trabalho é dada ênfase ao setor estudado. Faz-se uma contextualização do mercado de construção civil e, em seguida, apresentam-se as empresas estudadas. Analisa-se, então, o caso em questão e, finalmente, resumem-se os resultados obtidos.

\subsection{0 mercado da construção civil}

A Construção Civil é integrada por uma série de atividades complexas, ligadas entre si pela diversificação de produtos, com processos com graus variados de originalidade, vinculando-se a diferentes tipos de demanda. Geralmente, a Indústria da Construção Civil é classificada nos seguintes subsetores: i) Materiais de Construção; ii) Edificações; e iii) Construção Pesada (SEBRAE-MG, 2005). 
A Indústria da Construção Civil é um setor importante para o crescimento e desenvolvimento nacional devido a especificidades como: (i) elevado efeito multiplicador; (ii) menor necessidade de investimento, devido à baixa relação capital/produto; (iii) utilização intensiva de mão-de-obra, incluindo a não qualificada; (iv) responsabilidade por significativa parte dos investimentos; e (v) reduzido coeficiente de importação (CBIC, 2004).

Trata-se de uma indústria composta por uma complexa cadeia produtiva, que abrange setores industriais diversos. Um perfil setorial da construção civil brasileira, elaborado pelo SEBRAE-MG (2005), apresenta as seguintes características do setor: (i) a demanda apresenta forte correlação com a evolução da renda interna e condições de crédito; (ii) intensiva geração do emprego, principalmente para mão-de-obra não qualificada; (iii) apresenta níveis de competitividade e produtividade abaixo do padrão existente nos países desenvolvidos; e (iv) apresenta baixa atualização nos aspectos tecnológicos e de gestão em relação aos padrões dos países desenvolvidos.

O setor é marcado pela utilização de subempreiteiras que, por suas características, estão dentro do perfil de micro e pequenas empresas, ficando possivelmente submissas nas relações com as construtoras. As subempreiteiras da construção civil são caracterizadas, em sua grande maioria, pela pequena agregação tecnológica e pela precariedade no atendimento da legislação trabalhista e das condições de trabalho (MELLO, 2007).

\subsection{Unidades de análise}

A unidade de estudo deste trabalho é a Empresa X, que atua, preferencialmente, no Rio Grande do Sul, em Minas Gerais, no Rio de Janeiro e em São Paulo. Trata-se de uma das maiores organizações brasileiras de construção civil que atua no sub-setor de edificações. A Empresa X apresenta um faturamento anual de $\mathrm{R} \$ 800.000 .000,00$ com lançamentos de $500.000 \mathrm{~m}^{2}$ em empreendimentos residenciais de alto e médio padrão, shopping centers, edifícios comerciais, conjuntos de hotelaria e centros de exposições.

No mercado carioca, a Empresa X utiliza-se dos serviços da Metalúrgica $Z$ para fabricação e colocação das esquadrias e painéis metálicos. Os painéis metálicos substituem o uso do concreto aparente, permitindo que as fachadas tenham soluções que aliam facilidade de montagem e manutenção, leveza, alta resistência e durabilidade. O material utilizado é o alumínio devido a sua condição de maleabilidade, característica que dá a esse painel metálico grande facilidade de conformação. É utilizado na definição de revestimentos para fachadas e interiores de prédios industriais e comerciais. A Metalúrgica $\mathrm{Z}$ é uma pequena empresa de capital nacional, fundada em 1992 por ex-funcionário da Empresa X. Atualmente, possui dez funcionários fixos e se o volume de obras aumenta utiliza mão-de-obra terceirizada. Seu faturamento é de aproximadamente $\mathrm{R} \$ 300.000,00$ anuais.

\section{Aas dimensões comportamentais e políticas do poder e da confiança, além do conflito e dependência entre fornecedores e compradores.}

Atualmente, o segmento dedicado a esquadrias e painéis metálicos passa por transformações. Os fabricantes deste produto buscam associar-se, visando o desenvolvimento de normas técnicas, padrões de qualidade, padrões de segurança em fabricação e montagem, desenvolvimento de tecnologia e a busca de financiamento para estas atividades. Além disto, há um movimento de entrada de grandes fabricantes nacionais e estrangeiros para $o$ atendimento das encomendas, dificultando a sobrevivência das pequenas e médias empresas.

\subsection{Análise do estudo de caso}

A Metalúrgica $\mathrm{Z}$ foi fundada por um ex-funcionário da empresa de construção civil X, de modo que, de início, houve facilidades para que a empresa fabricasse a maior parte das encomendas destinadas às obras da construtora $\mathrm{X}$ sediadas no Rio de Janeiro. De fato, havia, em termos de parceria, um acordo informal entre as empresas pelo qual a Metalúrgica $\mathrm{Z}$ se comprometia a não fornecer seus serviços e produtos a concorrentes de X, que lhe daria preferência no suprimento. Ainda, as exigências técnicas da construtora não eram tão acentuadas como agora, já que a oferta do produto era feita por empresas de porte similar ao da metalúrgica. Assim, com base no relacionamento de amizade entre as partes, inicialmente, procurou-se estabelecer uma cadeia colaborativa. As empresas buscaram uma aliança de fornecimento, já que tinham como objetivo principal aproveitar a economia de escala e a especialização através do fornecimento de produtos e serviços entre parceiros.

A maior parte da produção da Metalúrgica Z, atualmente, é destinada para a empresa de construção civil X. Porém, não se observa mais $o$ antigo relacionamento de amizade entre as partes. A Metalúrgica $\mathrm{Z}$ tem alta percentagem de transações com o comprador. Além disto, com a entrada de grandes fabricantes houve uma modificação das exigências 
da construtora quanto a especificações técnicas, desenvolvimento de Pesquisa e Desenvolvimento em novas tecnologias de montagem e fabricação dos painéis que a Metalúrgica $Z$ não tem condições técnicas e financeiras de atender. Desta forma, o relacionamento entre a Metalúrgica $\mathrm{Z}$ e a Empresa $\mathrm{X}$ pode ser considerado como sendo assimétrico, havendo uma alta autoridade do comprador e baixa autoridade do fornecedor. Segundo a classificação de Cox e Chicksand (2005), existe uma dominação exercida pelo comprador. Logo, o estudo de caso corrobora a proposta de Hingley (2005) de que o comprador costuma ser a parte favorecida em relacionamento assimétrico.

Inicialmente, a assimetria do relacionamento não impedia que a Metalúrgica $Z$, que é o elo mais fraco desta cadeia, também se beneficiasse desta relação. A metalúrgica tolerava a situação em virtude das vantagens que a Empresa X lhe proporcionava: ganhava a maioria das encomendas destinadas às obras da construtora X sediadas no Rio de Janeiro. A relação era, então, legitimada e tem se sustentado por um longo período - 15 anos. No entanto, atualmente, não existe mais o objetivo de promover o interesse comum de ambas as partes no relacionamento entre a Empresa X e a Metalúrgica Z.

Identifica-se um desinteresse da construtora $\mathrm{X}$ em continuar com o relacionamento, já que faz maiores exigências em relação à Metalúrgica X e, mesmo sabendo que esta não tem condições de atendê-las por falta de condições técnicas e financeiras, não procura auxiliá-la em sua capacitação. $\mathrm{O}$ sucesso desta relação parece depender do entendimento do parceiro de maior poder em investir no fortalecimento do relacionamento. Faltam componentes básicos, prescritos por Child e Faulkner (1998), para manter uma relação baseada na confiança e cooperação, sendo essencial a existência de uma predisposição em investir de forma segura e compartilhar informações. Não houve investimento dos participantes para a evolução do relacionamento.

$\mathrm{O}$ início do relacionamento entre a construtora $\mathrm{X}$ e a metalúrgica era marcado pela confiança pessoal, uma vez que a Metalúrgica $\mathrm{Z}$ foi fundada por um ex-funcionário da construtora. $\mathrm{O}$ diretor da metalúrgica destaca que mantinha um bom relacionamento com seus ex-colegas da Empresa X. Assim, tal como propõe Bachmann (2001), a confiança pessoal foi essencial no início das relações entre as duas unidades analisadas. Contudo, como o mesmo autor e Nielsen (2004) defendem, a confiança pessoal não pode ser o principal sustentáculo de um relacionamento interempresarial.

Atualmente, constata-se que a construtora $\mathrm{X}$ baseia seu relacionamento na utilização do poder, usando o poder coercitivo (FRENCH; RAVEN, 1959). No entanto, este é um mecanismo frágil para sustentação de relações interorganizacionais. Para a prosperidade deste tipo de relacionamento, é necessário que haja uma combinação eficiente do poder e da confiança (BACHMANN, 2001; HINGLEY, 2005).

$O$ fracasso da tentativa de relação colaborativa entre as empresas estudadas pode ser explicado, também, devido à discrepância no tamanho das firmas. A Empresa X utiliza seu porte e volume de compras em relação ao fornecedor $\mathrm{Z}$ para conseguir vantagens como: (i) preços menores; (ii) maiores prazos de pagamento; (iii) cancelamento de pedidos sem aviso; (iv) interferência nos programas de produção; (v) exigência de exclusividade de serviços e produtos; (vi) requerimentos sobre a qualidade dos produtos e certificações de qualidade; e (vii) transferência de estoque. A parte mais fraca e dependente assume maior risco neste relacionamento assimétrico. A Metalúrgica $Z$ entende perfeitamente a situação, porém é obrigada a aceitá-la. A firma X é seu maior cliente e, devido ao entendimento havido, não pode fornecer produtos e serviços aos seus concorrentes. Ainda, como os custos de troca são baixos, seu produto pode ser fornecido por outros fornecedores rapidamente.

Em entrevistas realizadas, nota-se a assimetria deste relacionamento, em que existe por parte da empresa de construção civil uma relação de dominação e autoridade. O dono da empresa $Z$ sabe que precisa diversificar sua linha de produtos e de clientes, buscando desenvolver produtos de tecnologia mais avançada. Porém, no momento, não tem capital para tais investimentos. Ele tem conhecimento sobre a necessidade de novos conhecimentos e ferramentas que permitam o desenvolvimento de novos produtos e processos. No entanto, a maior necessidade no momento é conseguir capital para financiar estes desenvolvimentos. Para tanto, a Metalúrgica $\mathrm{Z}$ busca contato com fontes de financiamento. A empresa reconhece que há uma grande dependência dos pedidos da construtora X e esta situação a coloca em posição de risco. Por isto, busca alternativas de negócios. Entretanto, a Metalúrgica $\mathrm{Z}$ não quer abandonar a relação com a Empresa $\mathrm{X}$, pois reconhece que, apesar de assimétrica, esta também lhe traz vantagens. Por sua vez, a construtora $\mathrm{X}$ não parece disposta a investir na manutenção do relacionamento.

O sucesso do relacionamento também é dificultado pelas características do setor da construção civil. Trata-se de um mercado darwiniano, no qual os princípios da seleção natural levam à sobrevivência apenas das empresas mais ajustadas às necessidades do cliente. É crescente o aumento da concorrência neste setor. Assim, as empresas buscam cada vez mais apropriar valor a suas relações. Ao contrário do que pregam Coughlan et al. (2002), estas empresas não estão dispostas a "sacrificar-se para manter o relacionamento e para fazê-lo crescer", devido à hipercompetição. No caso estudado, a Metalúrgica $\mathrm{Z}$ exerce os cinco tipos de controle apresentados por Munson et al. (1999). 
A Metalúrgica Z, considerando o fato de estar num relacionamento de dominação por parte da Empresa X, deve procurar um reposicionamento para sua estratégia empresarial. Assim, a metalúrgica deve buscar uma análise de suas capacidades e considerar a utilização de uma das três abordagens estratégicas genéricas sugeridas por Porter (1986): liderança no custo total, diferenciação ou enfoque.

O Quadro 1 tem como objetivo apresentar as principais categorias emergentes do caso analisado resultantes da análise de conteúdo das entrevistas realizadas.

\subsection{Implicações dos resultados do estudo de caso para a gestão da cadeia de suprimentos da indústria da construção civil}

Nesta pesquisa, foi realizado o estudo de caso em apenas um elo de uma cadeia da construção civil. De tal maneira, os resultados não podem ser generalizados para toda a cadeia de suprimentos da indústria. Esta é uma característica comum em pesquisas que adotam o estudo de caso como estratégia de investigação. Os resultados também não podem ser generalizados porque as relações interorganizacionais variam de acordo com a estrutura e características de cada elo da cadeia. Assim, é preciso analisar a estrutura de cada cadeia para compreender como suas relações se constituem. No entanto, apesar dos resultados do estudo de caso em questão não serem abrangentes para toda a cadeia da construção civil, ainda assim permitem algumas análises com relação à gestão da cadeia de suprimentos da indústria da construção civil.

O relacionamento do elo da cadeia produtiva da construção civil, analisada no estudo de caso, baseia-se, predominantemente, na relação de dominação. Acredita-se que esta seja uma tendência na indústria da construção civil, uma vez que este setor é marcado pela utilização de subempreiteiras de micro e pequeno porte. A discrepância no tamanho das firmas, tal como ocorria no elo da cadeia analisado e tende a ser uma tendência na relação entre grandes construtoras e subempreiteiras, foi percebida como um dos fatores que estimulam o desenvolvimento de relações de poder e dominação. As grandes construtoras - assim como a Empresa $\mathrm{X}$ - costumam utilizar seu porte e volume de compras para conseguir vantagens.

A indústria da construção civil tem poucos compradores (grandes construtores) e muitos fornecedores (subempreiteiras), tal como no caso analisado. Esta característica contribui para a dependência do fornecedor, agravada ainda mais pelo fato de que a maioria das subempreiteiras da construção civil tem pequena agregação tecnológica (MELLO, 2007). Desta forma, estas subempreiteiras costumam ser submissas nas relações com as construtoras.

\section{Quadro 1: Resumo da análise do estudo de caso.}

Categorias Finais

Confiança e Cooperação
Observações

- O início do relacionamento entre a Empresa X e a Metalúrgica Z era marcado pela confiança pessoal, pois o fundador de $Z$ é um ex-funcionário da construtora;

- A confiança pessoal foi essencial no início das relações entre as empresas;

- A confiança pessoal não implicou no desenvolvimento de confiança sistêmica;

- A confiança pessoal não sustentou o relacionamento interempresarial.

Poder e dominação

- A construtora $X$ dava preferência de suprimento para a Metalúrgica $Z$ com a condição de que esta não fornecesse para seus concorrentes;

- A construtora $X$ tem alta autoridade no relacionamento, de modo que há dominação por parte do comprador;

- Atualmente, $X$ baseia seu relacionamento na utilização do poder coercitivo;

- A Empresa X utiliza seu porte e volume de compras em relação ao fornecedor Z para conseguir vantagens.

Dependência

- A maior parte da produção da Metalúrgica Z é destinada para a Empresa X;

- O relacionamento entre X e Z é assimétrico, havendo alta autoridade do comprador;

- Há maior dependência por parte do fornecedor;

- 0 custo de troca do fornecedor é relativamente baixo;

- Novos fornecedores, de maior porte, surgem no mercado, o que provocou maior exigência por parte da construtora $X$.

- Z, por ser mais fraca e dependente, assume maior risco no relacionamento. 


\section{CONSIDERAÇÕES FINAIS}

No presente trabalho, foram definidos os conceitos de cooperação, poder e dominação, analisando suas influências no relacionamento na cadeia de suprimentos. Esta pesquisa propõe-se a analisar a relevância dos relacionamentos na cadeia de suprimentos, tentando identificá-los como relações de dominação ou cooperação. Para tanto, identificouse uma fundamentação teórica para entender os principais fatores que influenciam tais relacionamentos, analisando as opiniões conflitantes de pesquisadores da área, e estendendo os conceitos estudados para um estudo de caso na cadeia da construção civil.

O poder, como um construto de relações interfirmas, tem recebido um tratamento irregular e conflitante por parte dos estudiosos. Entretanto, a revisão da literatura aponta que algumas pesquisas têm considerado a relevância da relação de poder na cadeia de suprimento (COX, 1999; COX; CHICKSAND, 2005; HINGLEY, 2005). Contudo, estes autores ainda são minoria. Hingley (2005) afirma haver uma lacuna na literatura sobre o papel do poder e da dominação nas relações interfirmas.

Conclui-se, então, que a visão da colaboração em cadeias de suprimentos, conforme encontrada na maior parte da literatura existente, traz uma ideologia gerencial de como as organizações deveriam interagir, sem descrever como estas relações de fato ocorrem. Hingley (2005) alerta sobre o risco de considerar que o relacionamento da cadeia ocorre apenas com base na cooperação e na confiança, dado que esta abordagem ignora relações existentes que são muito apropriadas para certos contextos.

Em suma, fica clara a importância do poder como um construto das relações entre os membros da cadeia de suprimentos. O relacionamento nas cadeias se desenvolve através de complexas relações de dependência, poder, dominação e cooperação. Entretanto, estas relações variam segundo a estrutura e características da cadeia, não sendo possível a generalização dos relacionamentos na cadeia simplesmente como relações de dominação ou de cooperação. Deve-se analisar a estrutura de cada cadeia específica para compreender como suas relações se constituem. O poder e a confiança são mecanismos de coordenação das relações na cadeia de suprimentos que tendem a coexistir.

O estudo de caso, realizado em um elo da cadeia produtiva da construção civil, demonstra que o relacionamento existente se baseia, predominantemente, na relação de dominação, devido a fatores inerentes ao setor como: grande poder de barganha imposto pelas construtoras, o perfil das empresas subempreiteiras ser de micro e pequenas empresas e pequena agregação tecnológica nos produtos fornecidos pelas subempreiteiras. Entretanto, destaca-se que, em alguns aspectos, o relacionamento também apresenta características de confiança. Ressalta-se que, para o caso em estudo, é importante a busca pelo comprometimento dos membros da cadeia, pelo conhecimento compartilhado, a dependência mútua e o planejamento conjunto.

A diversidade das relações na cadeia de suprimentos dificulta a generalização dos desafios encontrados pelos executivos no desenvolvimento de estratégias abrangentes para a cadeia. Assim, nem sempre as práticas adotadas em uma cadeia podem ser replicadas com sucesso em outras configurações. O relacionamento nas cadeias é essencial para a compreensão das fronteiras organizacionais. Para que os profissionais de logística saibam como as cadeias devem ser gerenciadas operacional e estrategicamente, torna-se fundamental a compreensão das estruturas de poder e dos relacionamentos existentes. Desta forma, a discussão sobre estes tópicos deve ser ampliada. Apenas através da compreensão da estrutura de poder entre fornecedores e compradores na busca de apropriação de valor em cadeias de suprimentos é que se pode compreender o verdadeiro ambiente operacional e estratégico das cadeias.

\section{Artigo recebido em 07/05/2007 Aprovado para publicação em 26/03/2009}

\section{REFERÊNCIAS}

AXELROD, R. The evolution of cooperation. New York: Basic Books, 1983.

BACHMANN, R. Trust, power and control in trans-organizational relations. Organization Studies, v. 22, n. 2, p. 337-365, 2001.

BARDIN, L. Análise de Conteúdo. Lisboa: Edições 70, 1977.
BARNEY, J.; HANSEN, M. Trustworthiness as a source of competitive advantage. Strategic Management Journal, v. 15, p. 175190, 1994

BEGNIS, H.; PEDROZO, E.; ESTIVALETE, V. Cooperação enquanto estratégia segundo diferentes perspectivas teóricas. Anais do ENAMPAD 2005. BRASÍLIA/DF, 27 a 29/07/2005, 16 p.

BENBASAT, I.; GOLDSTEIN, D. K.; MEAD, M. The case research strategy in studies of information systems, MIS Quarterly, September, p. 368-387, 1987. 
BERTHON, P.; PITT, L.; EWING, M.; BAKKELAND, G. Norms and power in marketing relationships: alternative theories and empirical evidence. Journal of Business Research, v. 56, n. 9, p. 699-709, 2003.

BLOIS, K. Don't all firms have relationships? Journal of Business and Industrial Marketing, v. 13, n. 3, p. 256-270, 1998.

BOWERSOX, D.; CLOSS, D. Logística empresarial: o processo de integração da cadeia de suprimento. São Paulo: Atlas, 2001.

CÂMARA BRASILEIRA DA CONSTRUÇÃO CIVIL. Disponível em: http://www.cbic.org.br. Acesso em 30/7/2007.

CAMPBELL, A. Buyer-supplier partnerships: flip sides of the same coin? Journal of Business and Industrial Marketing, v. 12, n. 6, p. 417-434, 1997.

CHILD, J.; FAULKNER, D. Strategies of cooperation: managing alliances, networks and joint ventures. Oxford: Oxford University Press, 1998.

COUGHLAN, A.; ANDERSON, E.; STERN, L.; EL-ANSARY, A. Canais de marketing e distribuição. Porto Alegre: Bookman, 2002.

COX, A. Power, value and supply chain management. Supply Chain Management: An International Journal, v. 4, n. 4, p. 167-175, 1999.
COX, A.; CHICKSAND, D. The Limits of Lean Management: Multiple Retailers and Farming Supply Chains. European Management Journal, v. 3, n. 6, p. 648-662, 2005.

FARIA, J. Economia Política do Poder. Curitiba: Juruá, v. 1, 2004.

FOLLET, M. Mary Parker Follet: Profeta do Gerenciamento. Uma celebração dos escritos dos anos 20. Rio de Janeiro: Qualitymark, 1997.

FRENCH, R.; RAVEN, B. The bases of social power. In: CARTWRIGHT, D. Studies in Social Power. Ann Arbor: University of Michigan Press, 1959.

HAGEN, J.; CHOE, S. Trust in Japanese interfirm relations: institutional sanctions matter. The Academy of Management Review, v. 23, n. 3, p. 589-600, 1998.

HINGLEY, M. Power to all our friends? Living the imbalance in supplier-retailer relationships. Industrial Marketing Management, v. 34, n. 2, p. 848-858, 2005.

LA PORTA, R.; LOPEZ-DE-SILANES, F.; SHLEIFER, A.; VISHNY, R. Trust in Large Organizations. American Economic Review, v. 87, n. 2, p. 333-38, 1997.
MELLO, L. Modernização das pequenas e médias empresas de construção civil: os impactos dos programas de melhoria de gestão da qualidade. Tese (Doutorado em Engenharia Civil) - PPGEC, Escola de Engenharia, UFF, 2007.

MILLS, J.; SCHMITZ, J.; FRIZELLE. A strategic review of "supply networks". International Journal of Operations \& Production Management, v. 24, n. 10, p. 1012-1036, 2004.

MUNSON, C.; ROSENBLATT, M.; ROSENBLATT, $Z$. The use and abuse of power in supply chains. Business Horizons, n.1, p. 55-65, 1999.

NIELSEN, B. The role of trust in collaborative relationships: a multidimensional approach. M@n@gement, v. 7, n. 3, p. 239-256, 2004.

PORTER, M. Estratégia competitiva: técnicas para análise da indústria e da concorrência. Rio de Janeiro: Campus, 1986.

SEBRAE-MG-SERVIÇO BRASILEIRO DE APOIO A MICRO E PEQUENA EMPRESAMINAS GERAIS. Perfil Setorial da Construção Civil-2005. Disponível em: http://www.sebraemg.com.br. Acesso em 26/2/2007.

YIN, R. K. Estudo de caso; planejamento e métodos. Porto Alegre: Bookman, 2001.

\section{SOBRE OS AUTORES}

\section{Renata Albergaria de Mello Bandeira}

Escola de Administração / PPGA / UFRGS

End.: Rua Washington Luiz 855, sala 317, Centro - 90010-460 - Porto Alegre - RS - Brasil

Tel.: (51) 3316-3833 Fax: (51) 3316-3833

E-mail: re.albergaria@gmail.com

\section{Luiz Carlos Brasil de Brito Mello}

Escola de Engenharia / Departamento de Engenharia de Produção/UFF

End.: Rua Passo da Pátria,156, sala 241, Bloco D - Niterói - RJ

Tel.: (21) 2512-2342

E-mail: luiz.brasil@gmail.com

\section{Antonio Carlos Gastaud Maçada}

Escola de Administração / PPGA/UFRGS

End.: Rua Washington Luiz 855, sala 317, Centro - 90010-460 - Porto Alegre - RS - Brasil

Tel.: (51) 3316-3833 Fax: (51) 3316-3833

E-mail: acgmacada@ea.ufrgs.br 